to infant health which may follow improper feeding of young infants. If some of the current preoccupation with child development could be transferred to the field of child nutrition, overnutrition and obesity might become things of the past and a slimmer and probably healthier child population might soon result.

In their discussion the authors state that "whether excessive dietary protein is harmful to babies is uncertain at present." To my knowledge there is no evidence that it is beneficial-why take chances? If there is the least doubt that it may be harmful (considerable elevations of blood urea and amino-acid levels can occur in cow's-milkfed babies), then it would seem sensible that non-human-milk-fed infants (the majority) should take only substitute milks containing near-physiological amounts of protein (in the range $1.5-1.8 \%$ against $3.5 \%$ for unmodified cow's milk and $1.2 \%$ for human milk). The use of such modified and less unphysiological milks would have other advantages for the young infants; their lowered phosphorus content mitigates against disturbed calcium: phosphorus homoeostasis and in the case of one at least of these adapted milks there is evidence of improved fat digestion and absorption. Such milks are more expensive, but not prohibitively so, and it is now to be our policy in the main maternity units of this area to recommend their use where natural feeding has failed or been declined for whatever reason. Every reasonable effort is still being made to promote breast-feeding ("breast-milk not beastmilk") and to ensure that parents know of the possibility of over-feeding, its recognition, its consequences, and its dangers. Particular stress is presently being laid on the avoidance of early non-milk solids and on the importance of reducing milk intake as solids increase in amount in the diet.

I can only hope that this clear and timely paper by Dr. Shukla and her co-authors will stimulate some equally clear thinking in high places on the necessity for rescuing medical and nursing interest in infant feeding from the deplorably low state to which it has fallen in recent years. I am quite certain that most parents, however misguided and badly advised they may seem to be in some cases at present, are only waiting for a lead and are anxious to do what is best for the nutrition of their infants. Let us hope that professional health workers are equally ready to play their part in imparting proper advice.-I am, etc.,

Cheltenham

R. D. G. CREery

SIR,-Infant feeding has been subject to the dictates of fashion for centuries so we cannot expect to be exempt today. Overfeeding has been a bogey for as long. Before bacteria were discovered it was held to be the cause of gastroenteritis, the scourge of infancy. However, even in this century Truby King was able to get away with the ridiculous comment that "in the breast-fed baby overfeeding is more common and more dangerous than underfeeding" and this attitude persisted until after the second world war. In $1952^{1}$ I reported an investigation of a series of 503 babies, $26 \%$ of whom had been diagnosed as overfed before they were two months old. Subsequent appraisal showed that in the vast majority unsatisfied hunger had been the cause of the symptoms and a reduction of the feeds had usually aggravated the condition. This confusion is less surprising when one remembers that standard textbooks enumerate the same symptoms for over- and under-feeding - namely, vomiting, the passage of loose stools, and loss of weight. Since then, until recently, babies have enjoyed far more liberal feeding regimens with the advent of self-demand schedules and the ever-earlier introduction of solids, but there are now signs that the pendulum is beginning to swing back to wards the Truby King approach with increased enthusiasm, since almost all our babies are now bottle-fed.

In their article Dr. Annapurna Shukla and her colleagues (2 December, p. 507) showed that $44.4 \%$ of their series of babies were "overweight" as compared with standards laid down by the Department of Health and Social Security. Their findings could, more convincingly I believe, be used to claim that the Department's standards are set too low because they are based upon a series of babies which included a significant proportion whose progress had been impeded by neonatal difficulties and or subsequent orthodox feeding restrictions. In another paper I drew attention to the "stoking-up period," a self-limited spell of rapid gain in weight in the first three months of life during which healthy babies on unrestricted feeds gain weight faster than is commonly appreciated. Only 214 out of 503 infants qualified for the unimpeded progress group, though no doubt it could have been further whittled down had more information been available. In other words, the majority of infants in this series of "normal" babies had sustained setbacks in the first two months of life, and any standards based upon their average rate of gain would be bound to be sub-optimal. Incidentally, of the eight babies who averaged a gain of $2 \mathrm{oz}(56 \mathrm{~g})$ or more daily, five were wholly breast-fed and only one was wholly bottle-fed.

Orthodox feeding regimens have bowed to the principle that small babies have weak digestions and cannot tolerate strong feeds. The instructions on packets of dried milk have prescribed diluted milk for small infants, who are only permitted to graduate to a full-strength formula by the age of about six months (though they will probably have been taking solids long before this). Most small babies have a high potentiality for growth and a small-capacity stomach which can only fulfil that potentiality if super-strength milk, solids, or continuous drip feeds are given. The prevalence of the early introduction of solids in Dr. Shukla's series explains why her babies put the standards to shame. It is highly significant that there was a marked disparity between the standard figures and her group with regard to the caloric intake of babies under three months, whereas there was virtually no difference for older babies, indicating that her group had the opportunity of taking the advantage of the stoking-up period. Thereafter the intake and the rate of gain fall dramatically and there is no proof that these babies swell the ranks of obese adults, though it has been shown that babies who are fat in the second six months of life may do so. It has not been proved that extra food creates the extra complement of fat cells obese babies possess, and the familial tendency suggests that they are endowed with extra cells which "cry out" for extra food to fill them; alternatively it must be admitted that extra food might create extra brain cells, in which case the choice would seem to lie between becoming slim and dim or fat and bright.

The onus is on those who advocate curtailing infant's feeds to prove these highly speculative points before the clinician puts them into practice. In the clinic, what are we to say to a mother who is repeatedly awakened by her hungry baby in the middle of the night? If she feeds him she may be made to feel guilty and if she gives gripe water instead he will obtain no lasting relief-either way she will enjoy her baby less and he will be discontented from the start. Perhaps, to conform with present views, we shall have to prescribe anorectic drugs routinely for $44.4 \%$ of all young babies.-I am, etc.,

Stock,
Essex

IAN G. WICKES

1 Wickes, I. G., British Medical Journal, 1952, 2, Wickes, I. G., Archives of Disease in Childhood,
1952, 27, 449 .

\section{Clinitest Tablet Stricture of the Oesophagus}

SIR,-Clinitest tablets, used to detect glycosuria, are not generally considered to be dangerous and are sometimes kept in the same cupboard as medications. However, they contain $38 \%$ sodium hydroxide, which is very caustic to the oesophageal mucosa. Accidental ingestion, more common in children and the elderly, can lead to corrosive oesophagitis and stricture formation as the following case illustrates.

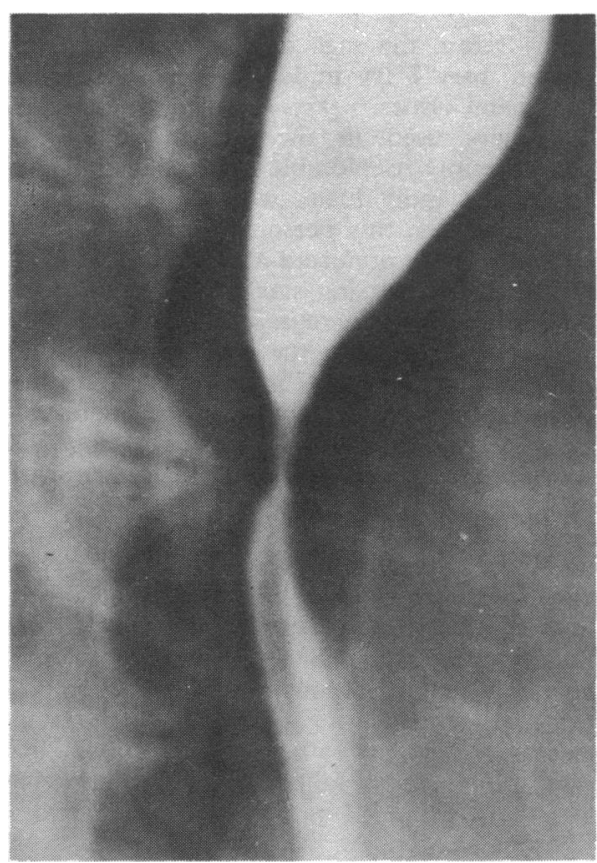

An 82-year-old diabetic woman with failing vision swallowed a Clinitest tablet, believing it to be aspirin, and immediately experienced a retrosternal burning pain. Three weeks later she was admitted to hospital with dysphagia for solids and liquids. A barium-swallow examination showed a narrow localized stricture at the level of the carina (see Fig.), which was confirmed at oesophagoscopy and dilated with bougies. Two further dilatations were necessary in the next month and periodic bouginage may be necessary in the future.

Fortunately, swallowed Clinitest tablets are more often than not washed down 
with a glass of water and no harm results. One man is reported to have taken one tablet with water four times a day for several weeks without ill effect." However, should oesophageal hold-up occur for more than a few seconds, localized thermal and caustic burning occurs as the tablet effervesces. Of 16 cases of Clinitest tablet ingestion reported in the literature, 13 were followed up; strictures developed in 11 of these, five of them in young children. Some were treated by repeated oesophageal bouginage, while others required segmental resection. ${ }^{2} 3$

To prevent accidental ingestion of Clinitest tablets I suggest that patients should be advised to keep their urine-testing tablets away from medications and out of the reach of children. It is important that the prescriber inform diabetics with poor vision who cannot read identifying labels that a Clinitest bottle is easily recognized by the ridges palpable in its surface. These ridges indicate that the contents are poison.I am, etc., The Ipswich Hospital,
Ipswich

R. J. PAyten

1 Tomsovic, E. J., and David H., fournal of Pediatrics, 1958, 53, 608.

American Medical Association, S., foumal of the 3 Genesier, N., and Becker, M., Clinical Pediatrics, 1969, 8, i7A.

\section{Side Effects of the Pill}

SIR,-Your recent articles on the association between "the pill," carcinogenicity, thromboembolism, and infertility prompt me to write to you regarding the frequency with which side effects of the pill are seen in general practice. Hardly a day goes by without a young woman attending the surgery suffering from some side effect of the "combined" preparation. She may be worried by "breakthrough bleeding," loss of libido, depression, headache, or amenorrhoea.

I think it is true to say that the pill is probably as common a cause of amenorrhoea as is pregnancy. The amenorrhoea caused by a "weak" pill such as Ortho-Novin $1 / 50$, Norinyl-1, or Minovlar or a strongly progestogenic pill such as Anovlar can be worrying for a woman and confusing for her doctor. Secondary amenorrhoea caused by disturbance of the hypothalamic-pituitary axis after cessation of oral contraception can be a disaster to the woman wishing to conceive again, as pointed out by $\mathbf{M r}$. K. Vernon Bailey (25 November, p. 492). As a general practitioner working in a relatively young population, I have never seen a case of thromboembolism due to the pill. Dramatic and disastrous as it may be, it is relatively rare. Amenorrhoea, on the other hand, is a side effect seen probably weekly.

But the two most overwhelming side effects of the pill are surely loss of libido and headaches. Since becoming aware of these I have made a practice of inquiring about them when my female patients come for routine examination or repeat prescriptions. To my astonishment I have found that probably $50 \%$ of women admit to a complete loss of libido while they are on the pill. A decrease in libido might be considered acceptable, but a complete loss of sexual interest is surely a quite unacceptable side effect. Because of their fear of pregnancy many women will unhappily tolerate this state of affairs. In the past few months, however, women have been asking more frequently to stop the "combined" pill because of loss of libido, and I have even "cured" a case of secondary impotence in a male by removing the pill from his wife. Probably $5-10 \%$ of women on the pill suffer from what I term "withdrawal" headaches. These are unilateral, severe, and often accompanied by nausea and a compulsion to lie down. They usually occur on the second, third, or fourth day after stopping the pill to allow cyclical "menstruation." Most women seem to put up with them and to be unaware of their association with the oral contraceptive. In my experience changing pills may lead to a temporary improvement in the headaches, but after several cycles they usually recur. Clonidine may be of some benefit, but it seems illogical to me to give a patient iatrogenic headaches and then to treat her with an equally powerful drug which has side effects of its own.

It will be interesting to see what side effects the "progestogen only" pills will produce. They may be unlikely to cause thromboembolism; ${ }^{1}$ they are more likely to cause "breakthrough bleeding" and contraceptive failure. Unless they reduce the incidence of loss of libido and of headache their place in the family planning armentarium must be questionable.

An almost universal panacea the pill may be, and we all use it; an ideal contraceptive it most certainly is not.-I am, etc.,

Norwich

David A. VARVEL

1 British Medical fournal, 1972, 4, 378

\section{Coxsackie B Virus and Diabetes}

SIR,-Gamble et al. ${ }^{2}$ reported a possible relationship between Coxsackie group B viruses and the onset of insulin-dependent diabetes. To prove an association between a virus infection and the onset of diabetes mellitus it would be necessary: (1) to isolate the same virus from a number of patients at the time of onset of their diabetes, or (2) to show a rising titre of viral antibody in patients' sera at this time, or (3) to show an epidemiological association between a viru epidemic and the onset of diabetes, or (4) to demonstrate a high viral antibody titre in patients' sera above the "background" level observed in the same population at the same time.

Because the onset of clinical diabetes may appear some time after a possible viral infection we considered that it was practicable to investigate only the third and fourth of the above criteria in relation to Coxsackie group B viruses. Fifty-eight newly diagnosed diabetic patients (whose clinical symptoms of the disease were severe enough to warrant admission to hospital) and 21 hospital patients in the same ward and matched for age by decade, who were not diabetic and whose blood sample was taken on the same day as from the diabetic patient, were investigated. We have also compared the results with those from 100 patients referred from medical outpatient departments to the virus laboratory with indefinite symptom thought possibly to have a viral aetiology over the same period.

The diabetic patients comprised 34 who subsequently required insulin therapy, 9 who could be controlled by dietary restriction alone, and 15 who received an oral hypoglycaemic agent in addition to dietary advice. Twenty-eight of these patients were under the age of 40 .

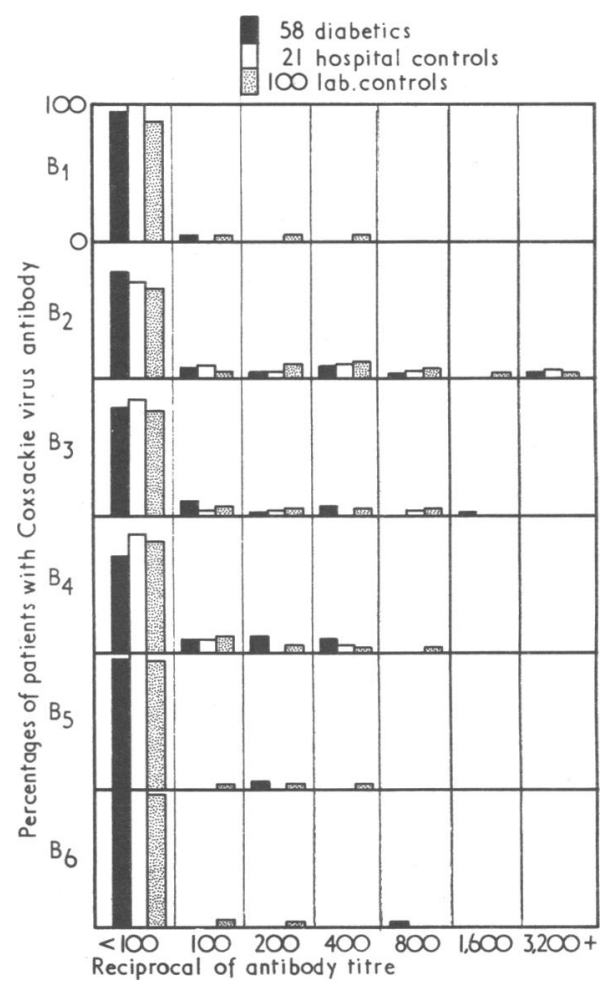

Comparison of Coxsackie group B virus neutralizing antibody titres in three groups of patients.

During the period of investigation no one Coxsackie group B virus predominated in Northern Ireland and a seasonal incidence of onset of new cases of diabetes was not present.

Neutralizing antibody to the six Coxsackie group B viruses was measured by mixing doubling dilutions of inactivated patients sera with equal volumes of 200 TCD $: 0_{\text {of }}$ virus and allowing the virus-serum mixtures to neutralize for three hours at $37^{\circ} \mathrm{C}$ before inoculation into cell cultures.

The distribution of neutralization titres is shown in the figure. There was no significant difference between the three groups; consideration of only those who required insulin treatment or were below the age of 40 did not alter this negative conclusion.

We have not been able to find any evidence to associate Coxsackie group $B$ virus infection and the clinical onset of diabetes mellitus.

D. R. HADDEN

J. H. CONNOLLY

D. A. D. MONTGOMERY

J. A. WEAVER

Royal Victoria Hospital,

Belfast

1 Gamble, D. R., Kinsley, M. L., Fitzgerald, M. G., Bolton,' R., and Taylor, K.' W., British Medical fournal, 1969, 3, 627. K. W., British
Gamble, D. R., and Taylor, K. W., Medical fournal, 1969, 3, 631 .

\section{Making Hospital Geriatrics Work}

SIR,-The success of Drs. H. M. Hodkinson and P. M. Jefferys (2 December, p. 536) in abolishing a geriatric waiting list merits congratulations. It is important to emphasize some of the circumstances in which this has been achieved. 